\title{
Supplemental Versus Permanent Nursing Staffing in Relation to Organizational Commitment
}

\author{
BADR B. MOHAMED, M.Sc. and FATMA A. ABED, D.N.Sc. \\ The Department of Nursing Administration, Faculty of Nursing, Cairo University
}

\begin{abstract}
Background: Nurse Shortages remain of concern because inadequate nurse staffing has been linked to poor quality of care and adverse patient outcomes. During periods of nursing shortage, hospital managers use nurses from temporary employment agencies to fill vacancies and to meet staffing needs. Supplemental nurses are hired with the expectation of maintaining planned staffing levels when scheduled staff is unavailable or the patient census fluctuates Supplemental registered nurses are similar to permanent $\mathrm{RNs}$ on numerous characteristics including education and experience. Because nurses are the main sources for continued success and performance for organization, building organizational commitment is undoubtedly very important for all organizations .
\end{abstract}

Aim: The current study conducted to compare supplemental versus permanent nursing staffing in relation to organizational commitment.

Subjects and Methods: A descriptive comparative design was utilized for this study to achieve the stated aim. The study was conducted at New Kaser El-Aini Teaching Hospital and El-Manial University Hospital. A sample of 301 convenient nurses was invited to participate in the questionnaire. For the purpose of this study, questionnaire for nurses was developed and utilized that consist of two parts: The first part was related to the nurse personal characteristics, the second part assess the nurses commitment level.

Results: The study showed that there was no statistical significance difference among permanent and temporary nurses regarding commitment level as general. The total means of temporary nurse's commitment is moderate (54\%). While total mean score of permanent nurse's commitment is moderate $(57 \%)$.

Conclusion: The study concluded that there was no statistical significant difference among permanent and temporary nurses regarding commitment level as supplemental and permanent staffing has moderate level of organizational commitment and the difference among two groups only regarding affective commitment.

Correspondence to: Dr. Badr B. Mohamed, The Department of Nursing Administration, Faculty of Nursing, Cairo University.
Recommendations: The current study recommended that Nursing administrators should gradually increasing the pay and absorbing the temporary employees to permanent employment whenever suitable, should provide temporary nurses with job trainings to equip them with skills so that they could be more productive.

Key Words: Supplemental nurses - Permanent nurses Organizational commitment.

\section{Introduction}

NURSE shortages remain of concern because inadequate nurse staffing has been linked to poor quality of care and adverse patient outcomes [1] . Agency for Healthcare Research and Quality (AHRQ) indicated recently that 44 percent of hospital nurses believed that there was not enough staff to handle the workload [3]. Many hospitals use both short-term daily (per diem) nurses and longer term "traveling" nurses employed by temporary employment agencies to meet staffing needs [4].

Supplemental Nursing Staff (SNS) is professional nurses belong to the same workplace, depend on the Nursing Management Team (NMT), don't have a fixed allocation unit and rotate throughout the various hospital units depending on the organization of work and usually have less professional experience but similar training [5] .

SRNs are more likely to have a baccalaureate degree compared with all staff nurses and baccalaureate education for nurses has been associated with better patient outcome SRNs have been found to be more efficient in some clinical practices, including evaluation of clinical outcomes, development of nursing diagnoses and therapeutic plans and documentation [6].

Permanent Employee is Worker who is employed and paid directly by the employer. In addi- 
tion to their wages they often receive benefits like subsidized health care, paid vacations, holidays, sick time, or contributions to a retirement plan. Permanent or standard employment: (i) employment is performed on a full-time basis; (ii) employment continues indefinitely; and (iii) employment is performed under the supervision of employers, at their place of business. Permanent employment provides relatively high degrees of security, continuity, and dependability for employees and organizations [7].

Any Organizations need effective managers and employees to achieve their objectives. They cannot succeed without their personnel efforts and commitment. Commitment of employees can be an important instrument for improving the performance of organizations [8].

Fostering organizational commitment among employees is very essential because employees who are highly committed toward their organizations are likely to stay longer, have better performance, and they tend to be highly involved at workplace committed employees show their loyalty and become productive individuals in their organizations As a result, such employees show positive attitude towards organizational goals and values and are likely to develop positive work behavior [9].

Organizational commitment is the psychological attachment felt by the person for the organization; it will reflect the degree to which the individual internalizes or adopts characteristics or perspectives of the organization. Organizational commitment therefore is the degree to which an individual psychologically attaches and identifies with an organization and correspondingly acts out in behavior resulting in involvement with the organization [10]

In general, an employee with strong commitment is commonly associated with a high intention of staying with an organization. Employees with high organizational commitment are.

More likely to be productive and hard-working [11].Research in this area is necessary to assess supplemental versus permanent nursing staff and at any level they committed to organization.

\section{Significance of the study:}

Supplemental nursing staffing becomes important source of nursing workforce in many ICU units due to nursing shortage. Supplemental nurses are employed to maintain or improve nurse staffing levels because better nurse staffing is associated with better patient outcomes Filling vacancies with supplemental nurses may improve hospital services by allowing shorter waiting periods for admission while ensuring that the desired nurse-to-patient staffing ratios are met. Loyalty of nursing staff either full time or part time to organization is critical issue as the success or failure of an organization is closely related to commitment to organization and its has been shown to be an important determinant in nurse job engagement and organizational goal achievements. It's important to examine the degree at which supplemental nurse committed to workplace compared to permanent staff because when the nurse become more committed she has willingness to achieve organizational objectives, success and nurses more likely to contribute to their organization's competitive advantage.

\section{Aim of the study:}

Compare supplemental versus permanent nursing staffing in relation to organizational commitment.

\section{Research question:}

The present study will be carried out to answer the following questions:

What's the organizational commitment level of supplemental nursing staffing?

What's the organizational commitment level of permanent nursing staffing?

\section{Subject and Methods}

\section{Research design:}

Descriptive comparative was utilized to achieve the aim of this study.

\section{Inclusion and Exclusion Criteria:}

All full time and part time nurses (male, female). work all shifts day and night shifts and work not less than 6 months in the unit.

\section{Setting:}

The current study was carried out in nine intensive care units at New El-kasr El-Aini teaching hospital and five intensive care units at El-Manial University Hospital from November 2016 to April 2017.

\section{Subjects:}

The number of the study sample was 301 nurses for the convenient sample. 


\section{Tools of data collection:}

It is composed of two parts as follows:

First part:

\section{Demographic data:}

Age, sex, level of education, marital status, years of experience \& salary, work status,childern presence, shift type, job rotation.

\section{Second part:}

Organizational commitment questionnaire adopted from [12]. To measure affective, continuance and normative organizational commitment. Alikert scale of ( $1=$ strongly disagree; $2=$ disagree; $3=$ neutral $4=$ agree; and $5=$ strongly agree) to measure participant degree of agreement and disagreement regarding three type of organizational commitment.

\section{Methods of data collection:}

- Consent to conduct the study was taking from the vice dean of graduate studies at Faculty of Nursing, Cairo university, and hospital administrator.

- The tools were reviewed by jury consisted of three professors in nursing administration to be tested for its content validity and necessary modification $\mathrm{s}$ were made.

- The investigator contacted to the nurses to explain the purpose and procedure of the study and determine the available time to collect data.

- The questionnaires were distributed to the studied sample during morning, afternoon and night shifts.

- Data collection was completed over a six months period. From Nov. 2016 to April 2017.

\section{Ethical Considerations:}

Before commencing the study, ethical approval was granted from the research ethics committee in which the study took place. The researchers ensured that the correct procedures were undertaken concerning informed consent, autonomy, anonymity and the maintenance of confidentiality.

\section{Statistical analysis:}

The collected data will be categorized, scored, tabulated, and analyzed by computer using statistical package for social science (SPSS). Descriptive statistics will be used in the form of frequency distribution and percentages. Appropriate statistical test were applied for data analysis.

\section{Results}

Table (1) shows that $(81.8 \%)$ of permanent staff are females, $(45.5 \%)$ of them are in the age group between $20<30$ years old and $35.4 \%$ of them have years of experience $<5$ years., as regard temporary staff $(57.3 \%)$ are male, $(70.9 \%)$ of them are in the age group between $20<30$ years old and $(79.6 \%)$ of them have years of experience $<5$ years.

Table (2) mentions that mean score of temporary nurses are (54.49). This means that there is moderate commitment level for temporary nurses.

Table (3) mentions that mean score of permanent nurses are (57.98) this means that there is moderate commitment level for permanent nurses.

Table (4) shows that there was no statistical significance difference among permanent and temporary nurses regarding commitment level.

Table (5) discuss that there is no significant difference among studied samples' marital status regarding affective, continuous and normative commitment.

Table (6) shows that there is statistical significant difference among studied samples' educational level regarding commitment level (.026) specific toward affective and normative $(.009, .005)$.

Table (1): Distribution of the study sample according to personal characteristics data $(\mathrm{N}=301)$.

\begin{tabular}{|c|c|c|c|c|}
\hline \multirow[t]{2}{*}{ Item } & \multicolumn{2}{|c|}{$\begin{array}{l}\text { Permanent } \\
(\mathrm{n}=198)\end{array}$} & \multicolumn{2}{|c|}{$\begin{array}{c}\text { Temporary } \\
(\mathrm{n}=103)\end{array}$} \\
\hline & No. & $\%$ & No. & $\%$ \\
\hline \multicolumn{5}{|l|}{ Sex: } \\
\hline Male & 36 & 18.2 & 59 & 57.3 \\
\hline Female & 162 & 81.8 & 44 & 42.7 \\
\hline \multicolumn{5}{|l|}{ Age: } \\
\hline $20<30$ year & 90 & 45.5 & 73 & 70.9 \\
\hline $30<40$ & 54 & 27.3 & 24 & 23.3 \\
\hline $40<50$ & 48 & 24.2 & 6 & 5.8 \\
\hline $50<60$ & 6 & 3.0 & 0 & 0 \\
\hline \multicolumn{5}{|c|}{ Years of experience: } \\
\hline$<5$ years & 70 & 35.4 & 82 & 79.6 \\
\hline $5<10$ years & 28 & 14.1 & 7 & 6.8 \\
\hline $10<15$ years & 25 & 12.6 & 2 & 1.9 \\
\hline $15<20$ years & 44 & 22.2 & 4 & 3.9 \\
\hline $20<25$ years & 11 & 5.6 & 3 & 2.9 \\
\hline 25 and more & 20 & 10.1 & 5 & 4.9 \\
\hline
\end{tabular}

Table (2): Means and standard deviation for Commitment dimensions of temporary nurses.

\begin{tabular}{lcccc}
\hline $\begin{array}{l}\text { Commitment } \\
\text { dimensions of } \\
\text { temporary nurses }\end{array}$ & Minimum & Maximum & Mean & SD \\
\hline Affective & 6.00 & 30 & 17.23 & 3.29 \\
Continuance & 6.00 & 30 & 18.90 & 3.97 \\
Normative & 6.00 & 30 & 18.34 & 3.63 \\
\hline Total & 18.00 & 90 & 54.48 & 8.80 \\
\hline
\end{tabular}


Table (3): Means and standard deviation for Commitment dimensions of permanent nurses.

\begin{tabular}{lcccc}
\hline $\begin{array}{l}\text { Commitment } \\
\text { dimensions of } \\
\text { temporary nurses }\end{array}$ & Minimum & Maximum & Mean & SD \\
\hline Affective & 6.00 & 30 & 19.90 & 3.29 \\
Continuance & 6.00 & 30 & 19.37 & 3.97 \\
Normative & 6.00 & 30 & 18.71 & 3.63 \\
\hline Total & 18.00 & 90 & 57.98 & 8.80 \\
\hline
\end{tabular}

Table (4): Difference between permanent and temporary nurses regarding organizational commitment dimensions.

\begin{tabular}{lcccl}
\hline Commitment & $\begin{array}{c}\text { Permanent } \\
\text { M-\}SD }\end{array}$ & $\begin{array}{c}\text { Temporary } \\
\text { M-\}SD }\end{array}$ & $t$ & $p$ \\
\hline Affective & $19.90-\{5.49$ & $17.23-\{3.29$ & -3.54 & .001 \\
Continuance & $19.37-\{5.78$ & $18.90-\{3.97$ & -.47 & .642 \\
Normative & $18.71-\{4.49$ & $18.34-\{3.63$ & .44 & .66 \\
\hline Total & 57.98 & 12.02 & 8.80 & 1.60 \\
\hline
\end{tabular}

Table (5): Relationship between the respondents' organizational commitment dimensions by their marital status $(\mathrm{N}=301)$.

\begin{tabular}{lll}
\hline Marital status & $\mathrm{F}$ & $p$ \\
\hline Affective & 1.90 & 1.29 \\
Continuance & 1.27 & .28 \\
Normative & 1.78 & .15 \\
\hline Total & 3.624 & .061 \\
\hline
\end{tabular}

Table (6): Relationship between the respondents' organizational commitment dimensions by their educational level $(\mathrm{N}=301)$.

\begin{tabular}{lll}
\hline Educational level & $\mathrm{F}$ & $p$ \\
\hline Affective & 3.42 & .009 \\
Continuance & .53 & .71 \\
Normative & 3.83 & .005 \\
\hline Total & 2.824 & .026 \\
\hline
\end{tabular}

\section{Discussion}

Regarding the social-demographic data of the study participants, the result of the current study revealed that the majority of the permanent staff are females, are between $20<40$ years old, have nursing experience ranged from $5<20$ years.

This result may be explained by the fact that (as regard permanent staff) nursing is a universal feminine profession as well as the enrolment of the male students in this profession was started in the late centuries. In addition, the first graduated male student from the Faculty of nursing Cairo University was at 2007. So, male nurses' numbers still until now very limited. Meanwhile, in Egypt the number of professional nurses who graduated from the faculties of nursing and/or the nurses who hold an associate's degree in nursing is hardly covered the Egyptian hospital work needs may be due to they prefer to work in private hospital for highly salary and newly professional graduated nurses tend most of the time to travel to work in other countries.

Furthermore, temporary staff becomes important phenomena in either gosvernmental or private hospital in these days and this due to sever nursing shortage that results in adverse outcomes for patient, nurse and organization. Most of temporary staff are male for their big responsibility as (may be student, from another governorate and learn in faculty of nursing in Cairo so they responsible for their studying and living fees).

The current study revealed that the total mean of temporary nurse's commitment is moderate (54\%) started by continuance commitment has highest score followed by normative and then affective commitment.

This study contradicts with Furåker et al., [13] who reported that Workers in temporary jobs reported higher levels of value commitment. Workers on fixed-term contracts were actually more committed than workers on open-ended contracts.

\section{This result classified as follow:}

The current study revealed that the total mean score of permanent nurse's commitment is moderate (57\%) started by affective commitment has highest score followed by continuance and then normative commitment. this mean that permanent nurses have moderate level of accepting goals, values of organization, willing to exert considerable effort on behalf of organization and have a high level of desiring to stay at organization. This study supported with Mohamed et al., [12] who reported that the.

Highest percentage of staff nurses were moderately to their organization having high affective commitment level and low continuance and normative commitment.

The current study revealed that there was no statistical significance difference among permanent and temporary nurses regarding commitment level as general. This contradicts with Howard et al., [14]. Who showed that there is statistically significant difference between traditional employees and 
independent contractors regarding commitment level? Employees are more committed to their organization than contractors.

However, there was difference among permanent and temporary nurses only regarding affective commitment. This contradicts with Josem et al., [15]. Who reported that there is no significant difference between permanent and temporary employees' in Affective Organizational commitment.

The findings of the present study revealed that there is no significant difference of studied samples' marital status regarding affective, continuous and normative commitment. These findings show that organizational commitment not affected by single, or married nurses. This may be due to commitment is crucial element in success of organization and achieve its objectives, also nursing personnel either single or married are responsible for achieve the organizational goals and mission so, they should exhibit loyalty and commitment to organization.

This study congruent with study by Khodadei et al., [16], who, showed that there was not significant relationship between the organizational commitment score and demographic variables of gender, marital status, university type, position, ward, and employment type.

As regard relationship between the nurses' organizational commitment and their educational level. The findings of the present study revealed that there is significant difference among studied samples' educational level regarding commitment level specific toward affective and normative commitment $(.009, .005)$.

This may be due to nursing staff with high educational level (baccalaureate, master degree have good reputation about their capabilities of self awareness, critical thinking, variety of knowledge and skills, autonomy and ability to make decision that enabling them to hold administrative position, receive enough salary that make them satisfied and committed to their.

Organization nurses with high educational level initiative and proceed toward change and make difference to improve organization image so, they emotionally attached to organization and feel guilt if they leave it. But low educational level nurses satisfy with status quo, fear of change and spend their shift as it's and fear to lose their job so; they aren't belonging to specific organization or attention to organization problems.
This result supported with Abebe et al., [17] Who indicate that there is a significant difference in the organizational commitment levels experienced by employees based on their education levels. In this instance, those with education levels BSc/ MA holders indicated the lowest organizational commitment relative to the other education levels.

Respondents with a $\mathrm{PhD}$ and above reported the highest levels of organizational commitment. This may be due to workers with higher educational qualification occupy higher ranks and therefore have more responsibilities which always requir emore commitment to the organization.

\section{Conclusion:}

The present study conducted to examine supplemental versus permanent nursing staffing in relation to organizational commitment in selected nursing care units. The study concluded that there was no difference among permanent and temporary nurses regarding commitment level as supplemental and permanent staffing had moderate level of organizational commitment and the difference among two groups only regarding affective commitment. The study admitted that there was highly statistical relation among studied samples' age regarding commitment level. Also, the study concluded that there was significant difference among studied samples' educational level regarding commitment level.

\section{Recommendations:}

In the light of the findings of the present study, the following were recommended: Nursing administrators should gradually increasing the pay and absorbing the temporary employees to.

Permanent employment whenever suitable, Nursing administrators should provide temporary nurses with job trainings to equip them with skills so that they could be more productive.

Also, nursing administrators should frequently review the compensation and benefits items for staff under short term contracts to enhance their loyalty and commitment to organization. Nursing administrators should maintain and enhance commitment level of temporary nurses by.

Improving their critical thinking, enhance their ability to be decision maker, to be leader, accept new ideas from them to make change and provide flexible scheduling.

\section{References}

1- Hanaysha J.: Testing the Effects of Employee Engagement, Work Environment, and Organizational Learning on 
Organizational Commitment. Procedia-Social and Behavioral Sciences, 229: 289-297, 2016.

2- NEEDLEMAN J., BUERHAUS P., PANKRATZ V.S., LEIBSON C.L., STEVENS S.R., and HARRIS M.: Nurse staffing and inpatient hospital mortality. New England Journal of Medicine, 364 (11): 1037-1045, 2011.

3- Agency for Healthcare Research and Quality (AHRQ). Hospital Survey onPatient Safety Culture: User Comparative Database Report. Rockville, M.D.: AHRQ 2010.

4- SEO S. and SPETZ J.: Demand for temporary agency nurses and nursing shortages. INQUIRY: The Journal of Health Care Organization, Provision, and Financing, 50 (3): 216-228, 2013.

5- AIKEN L.H., SHANG J., XUE Y. and SLOANE D.M.: Hospital Use of Agency-Employed Supplemental Nurses and Patient Mortality and Failure to Rescue. Health Services Research, 48 (3): 931-948, 2013.

6- XUE Y., CHAPPEL A.R., FREUND D.A., AIKEN L.H., and NOYES K.: Cost outcomes of supplemental nurse staffing in a large medical center. Journal of Nursing Care Quality, 30 (2): 130-137, 2015.

7- WILKIN C.L.: I can't get no job satisfaction: Meta_analysis comparing permanent and contingent workers. Journal of Organizational Behavior, 34 (1): 47-64, 2013.

8- BAHRAMI M.A., BARATI O., GHOROGHCHIAN M.S., et al.: Role of organizational climate on organizational commitment: The case ofteaching hospitals. Osong. Public. Health Res. Perspect. Apr., 7 (2): 96e100. 2016

9- DEY T., KUMAR A. and KUMAR Y.L.N.: A New Look at the Antecedents and Consequences of Organizational Commitment: A Conceptual Study, 2014.
10- FARRIS J. R.: Organizational commitment and job satisfaction: A quantitative investigation of the relationships between affective, continuance, and normative constructs (Doctoral dissertation, Capella University), 2012.

11- SHAHID A. and AZHAR S.M.: Gaining employee commitment: Linking to organizational effectiveness. Journal of Management Research, 5 (1): 250, 2013.

12- MOHAMED S. and EZZ-ELDEEN N.: Relationship between staff nurses job satisfaction and organizational commitment at new El-Kasar El-Ani Teatching Hospital, 2011.

13- FURÅKER B. and BERGLUND T.: Job Insecurity and Organizational Commitment. International Journal of Organizations/Revista Internacional de Organizaciones, (13), 2014.

14- HOWARD L. A.: Differences in organizational commitment between traditional employees and independent contractors (Doctoral dissertation, Capella University), 2016.

15- JOSE M.M.: A study of the Impact of Psychological contract on Organizational commitment among Temporary and Permanent Employees in Organizations. Journal of Contemporary Research in Management, 3 (2), 2012.

16- KHODADADEI N., REZAEI B. and SALEHI S.: Investigating the Relationship of Organizational Commitment and Clinical Competence (Case study: Nurses Working in Montazeri Hospital, City of Najafabad, Iran, 2015). Health Sciences, 5 (5), 308-316, 2016.

17- ABEBE T. and MAROS S.: The relationship between job satisfaction and organizational commitment in public higher education institution: The case of Arba Minch University, ethiopia Vol. 4, Issue 8, Aug, 17-36, 2016.

\section{العمالة التمريضية المؤقتة مقابل الدائمة وعلاقتها بالانتماء المؤسسى}

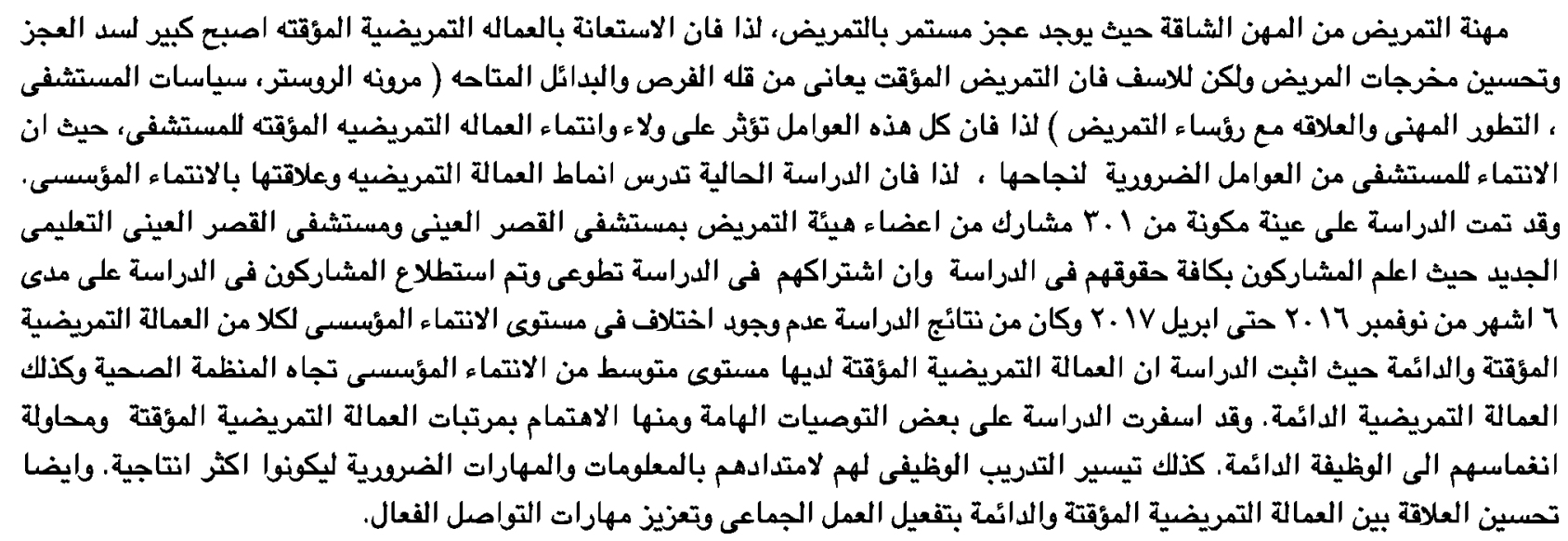

